\title{
p53 as a prognostic marker associated with the risk of mortality for oral squamous cell carcinoma
}

\author{
TOMMASO CUTILLI ${ }^{1}$, PIETRO LEOCATA ${ }^{2}$, VINCENZA DOLO $^{3}$ and EMMAALTOBELLI ${ }^{4}$ \\ ${ }^{1}$ Department of Life, Health and Environmental Sciences, Maxillofacial Surgery Unit; \\ ${ }^{2}$ Department of Life, Health and Environmental Sciences, Pathological Anatomy Unit; \\ ${ }^{3}$ Department of Life, Health and Environmental Sciences, Clinical Pathology Unit; \\ ${ }^{4}$ Department of Life, Health and Environmental Sciences, Medical Statistics and Epidemiology Unit, \\ University of L'Aquila, I-67100 L'Aquila, Italy
}

Received October 4, 2015; Accepted April 22, 2016

DOI: $10.3892 / \mathrm{ol} .2016 .4742$

\begin{abstract}
Oral squamous cell carcinoma (OSCC) is often associated with a poor prognosis. The purpose of the present study was to investigate survival and the risk of mortality in OSCC with regard to stage, tumor site and p53 expression. A retrospective study was performed on 150 non-consecutive cases of OSCC that were observed between January 1992 and January 2012, and were selected from a total of 580 patients according to the criteria of the homogeneity of histopathological grading (G2). The medical records were reviewed for 48 cases with disease at stage I [37 males, age 64.7 \pm 5.7 years (mean age \pm standard deviation); 11 females, age $70.0 \pm 3.37$ years]; 27 cases with stage II (15 males, age $64.5 \pm 5.6$ years; 12 females, age $69.2 \pm 3.9$ years); 58 cases with stage IVa (42 males, age $66.9 \pm 5.3$ years; 16 females, age $64.2 \pm 6.5$ years); and 17 cases with stage IVb (16 males, age $65.7 \pm 5.4$ years; 1 female, age 69 years). Monoclonal p53 antibody (clone DO-7) was used to perform the 553 immunohistochemical study. A significant association was found between the site of the tumor and p53 overexpression $(\mathrm{P}<0.0001)$. Stage I-II cases showed a higher cumulative probability of a 24-month survival time than stage IVa-IVb cases $(\mathrm{P}<0.0001)$. Cheek, floor and soft palate tumors showed a worse prognosis $(\mathrm{P}<0.0001)$ and tumors with p53 overexpression $>50 \%$ showed a poor survival rate $(\mathrm{P}<0.0001)$ compared with tumors of the attached gingiva, tongue and retromolar trigone. The findings allowed the quantification of the risk mortality from OSSC with regard to stage, tumor site and the p53 expression pattern of the tumor.
\end{abstract}

Correspondence to: Professor Tommaso Cutilli, Department of Life, Health and Environmental Sciences, Maxillofacial Surgery Unit, University of L' Aquila, Via Della Comunità Europea 13, I-67100 L'Aquila, Italy

E-mail: tommaso.cutilli@cc.univaq.it

Key words: squamous oral cell carcinoma, p53 protein, prognostic marker, risk of mortality, stage correlation
Data supported the absolute indications for wide surgical margins (radical surgery) in cases of T1-T2 N0 tumors of the tongue, floor, retromolar trigone and attached gingiva when p53 overexpression is $>50 \%$ in association with a higher risk of mortality compared with when p53 overexpression is $<50 \%$.

\section{Introduction}

Oral squamous cell carcinoma (OSCC) is among the 10 most common cancers worldwide and it is often associated with a poor prognosis despite the marked progress in surgical methods, particularly the introduction of microvascular reconstructive techniques, and the significant progress of chemotherapy and radiotherapy $(1,2)$. It should be emphasized that approximately two-thirds of cases are diagnosed at an advanced stage of disease (stage III-IV) and that tumor-node-metastasis (TNM) staging often does not explain the clinical behavior of the tumor (3-6). For this reason, several studies have been performed on the biological patterns of the tumor, which are closely connected with its behavior (greater or lesser aggressiveness) and can predict the prognosis. Oncogenes expressed at varying percentages and associated modifications of chromosomal sites have been identified in oral tumors (4-13). The p53 tumor suppressor gene (expressed in $4-50 \%$ of cases) is the most studied oncogene detected on chromosome 17, and it is clear that preliminary knowledge of the p53 status may be of great assistance in managing OSCC (14-18).

Following previous studies on $\mathrm{p} 53$, we were recently able to verify that p53 overexpression $>50 \%$ indicates a poor prognosis in advanced oral tumors (19-21). Indeed, p53 overexpression $>50 \%$, detected by the simple, reliable, routine examination of immunohistochemical analysis, is associated with a high probability of mutation in this tumor suppressor gene, with a poor response to sequential multimodality treatments (21).

However, it appears equally important to know the pattern of this marker in all stages of OSCC. The evolution of stage I-II is not yet well known with regard to the behavior of 
the advanced stages, with data concerning this derived only from clinical experience $(22,23)$.

It is not sufficient to know that clinically, an advanced stage of the tumor is more serious than an early stage. The risk of mortality must be quantifiable for all stages.

The purpose of the present study was to perform a survival analysis and investigate the risk of mortality with regard to variables such as tumor stage (stages I, II, IVa and IVb), oral tumor site and p53 expression in OSCC, in order to obtain useful information in addition to the classical factors of screening.

\section{Patients and methods}

A retrospective study of 150 non-consecutive cases of stage I, II, IVa and IVb OSCC that were observed and treated by resection between January 1992 and January 2012 in the Maxillofacial Surgery Operative Unit (San Salvatore City Hospital, L' Aquila, Italy), were selected from a total of 580 patients, according to the inclusion criteria of the homogeneity of G2 histopathological grading (G1, well-differentiated; G2, moderately-differentiated; and G3, undifferentiated). The G2 grading diagnosis was based on moderate cellular differentiation. The patients were all smokers.

Immunohistochemical staining procedures were performed according to the manufacturer's protocols. Paraffin sections (4- $\mu \mathrm{m}$ thick) were mounted on poly-L-lysine-coated glass slides, dewaxed, dehydrated, placed in $0.1 \mathrm{M}$ citrate buffer $(\mathrm{pH}, 0.6)$ and microwaved twice for $15 \mathrm{~min}$. Endogenous peroxidase activity was then blocked with $0.3 \%$ hydrogen peroxide in methanol for $30 \mathrm{~min}$. Incubation with monoclonal mouse anti-human antibodies against p53 (clone DO-7; catalog no. GA616; 1:50 dilution; Dako, Glostrup, Denmark) was then performed. Next, the sections were treated with streptavidin-biotin-peroxidase complex, follwed by immersion in diaminobenzidine- $\mathrm{H}_{2} \mathrm{O}_{2}$ substrate, for $5 \mathrm{~min}$ at room temperature, for chromogen development. The sections were finally counterstained with hematoxylin. A known p53-positive OSCC specimen was used as a positive control. Substitution of the primary antibody with non-immune serum served as a negative control.The p53 labeling index was calculated by assessing the nuclear immunopositivity in 1,000 neoplastic cell in 10 high-power fields using a double-headed micropscope (BX51; Olympus, Tokyo, Japan; this was considered positive when there was $\geq 10 \%$ immunostaining.

Cancer staging was performed in accordance with the 2002 American Joint Committee on Cancer sixth edition staging criteria (24).

Statistical analysis. Continuous variables are presented as mean \pm standard deviation and range. The differences in p53 expression levels according to the tumor site were evaluated using the non-parametric Kruskal-Wallis test.

Survival analysis was performed to describe the overall mortality, and prognostic factors were analyzed by univariate analysis. The product limit method (Kaplan-Meier) was used to evaluate the probability of survival to 24 months with respect to the following variables: Age, gender, site of tumor, TNM stage and p53 overexpression $>50 \%$. Differences

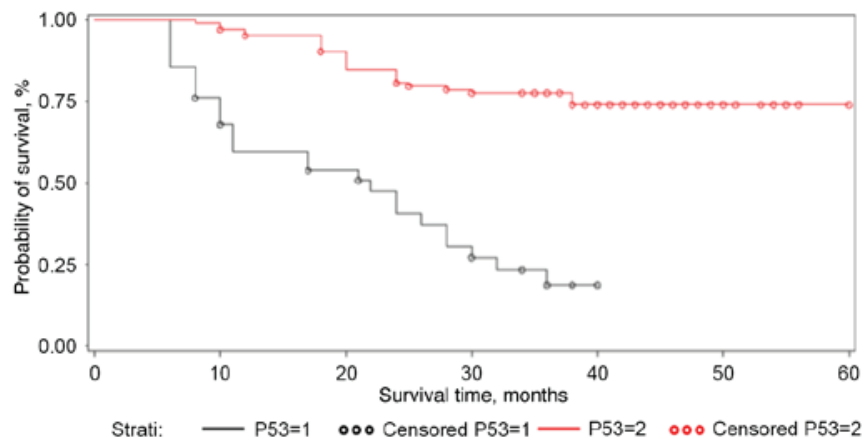

Figure 1. Product limit survival estimates (Kaplan-Meier) with regard to p53 expression, as determined by immunohistochemical analysis. Survival time is equivalent to duration of follow-up.

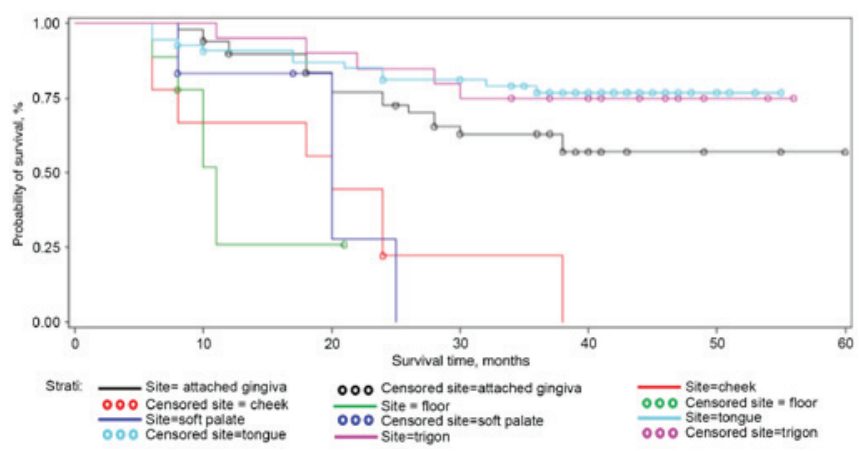

Figure 2. Product limit survival estimates (Kaplan-Meier) with regard to tumor site. Survival time is equivalent to duration of follow-up.

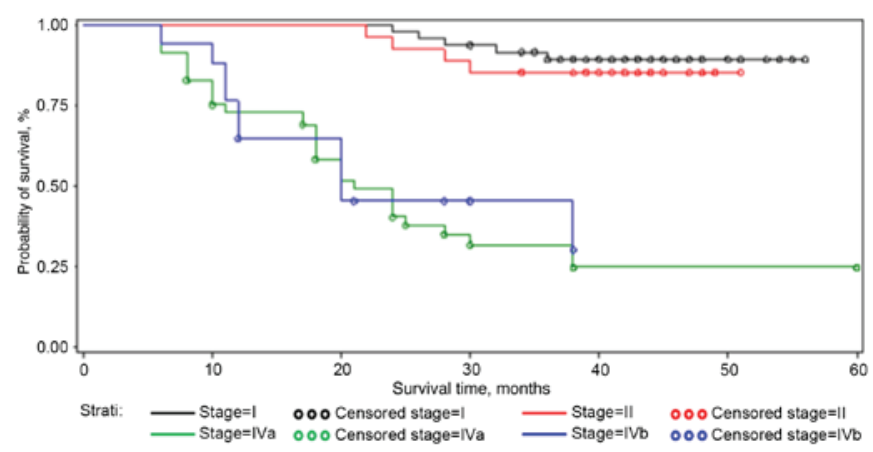

Figure 3. Product limit survival estimates (Kaplan-Meier) with regard to tumor stage. Survival time is equivalent to duration of follow-up.

between survival curves were assessed using the log-rank test. Multivariate (proportional hazard model) analysis was used to estimate prognostic variables and associated risks of mortality. The results have been expressed as the conditional relative risk of mortality and $95 \%$ confidence intervals. $\mathrm{P}<0.05$ was used to indicate a statistically significant difference, and statistical tests were performed using SAS/STAT 9.2 (SAS Institute Inc., Cary, NC, USA).

\section{Results}

The mean ages and age ranges of the patients were as follows: Stage I, 37 males (64.7 \pm 5.7 years; range, 54-75 years) and 11 females (70.0 \pm 3.37 years; range, 65-75 years); stage II, 
Table I. Survival analysis for clinical characteristics and p53 expression.

\begin{tabular}{|c|c|c|c|c|}
\hline Variable & $\begin{array}{l}\text { No. of patients } \\
(n=96,64 \%)\end{array}$ & $\begin{array}{l}\text { No. of mortalities } \\
\quad(\mathrm{n}=54,36 \%)\end{array}$ & $\begin{array}{l}\text { Cumulative probability of } \\
24 \text { months of survival, } \%\end{array}$ & $\begin{array}{l}\text { Log-rank test } \\
\text { (P-value) }\end{array}$ \\
\hline \multicolumn{5}{|l|}{ Age, years } \\
\hline$\leq 65$ & 36 & 32 & 63.9 & \multirow[t]{2}{*}{0.05} \\
\hline$>65$ & 60 & 22 & 76.2 & \\
\hline \multicolumn{5}{|l|}{ Gender } \\
\hline Male & 68 & 41 & 70.5 & \multirow[t]{2}{*}{0.65} \\
\hline Female & 28 & 13 & 70.1 & \\
\hline \multicolumn{5}{|l|}{ Stage } \\
\hline I & 43 & 5 & 97.9 & \multirow[t]{4}{*}{$<0.0001$} \\
\hline II & 23 & 4 & 96.3 & \\
\hline IVa & 23 & 35 & 40.2 & \\
\hline $\mathrm{IVb}$ & 7 & 10 & 45.2 & \\
\hline \multicolumn{5}{|l|}{ Site } \\
\hline Attached gingiva & 32 & 19 & 72.5 & \multirow[t]{6}{*}{$<0.0001$} \\
\hline Cheek & 1 & 8 & 22.2 & \\
\hline Floor & 3 & 6 & 25.9 & \\
\hline Soft palate & 2 & 4 & 27.8 & \\
\hline Tongue & 43 & 12 & 81.1 & \\
\hline Retromolar trigone & 15 & 5 & 85.0 & \\
\hline \multicolumn{5}{|l|}{ p53 expression, $\%$} \\
\hline$>50$ & 14 & 28 & 47.4 & \multirow[t]{2}{*}{$<0.0001$} \\
\hline$\leq 50$ & 82 & 26 & 80.8 & \\
\hline
\end{tabular}

Table II. Proportional hazards model according to variables considered.

\begin{tabular}{|c|c|c|c|c|c|}
\hline Variable & No. of patients & No. of mortalities & RR Cox model & $95 \% \mathrm{CI}$ & P-value \\
\hline \multicolumn{6}{|l|}{ Age, years } \\
\hline$<65$ & 36 & 32 & $1.00^{\mathrm{a}}$ & & \\
\hline$>65$ & 60 & 22 & 0.57 & $0.33-0.98$ & 0.04 \\
\hline \multicolumn{6}{|l|}{ Gender } \\
\hline Female & 68 & 41 & $1.00^{\mathrm{a}}$ & & \\
\hline Male & 28 & 13 & 0.86 & $0.46-1.61$ & 0.86 \\
\hline \multicolumn{6}{|l|}{ Stage } \\
\hline I & 43 & 5 & $1.00^{\mathrm{a}}$ & & \\
\hline II & 23 & 4 & 1.44 & $0.39-5.35$ & 0.59 \\
\hline IVa & 23 & 35 & 13.07 & $5.06-33.73$ & $<0.001$ \\
\hline $\mathrm{IVb}$ & 7 & 10 & 11.50 & $3.89-33.87$ & $<0.001$ \\
\hline \multicolumn{6}{|l|}{ Site } \\
\hline Retromolar trigone & 32 & 19 & $1.00^{\mathrm{a}}$ & & \\
\hline Tongue & 1 & 8 & 1.42 & $0.46-4.36$ & 0.54 \\
\hline Attached gingiva & 3 & 6 & 2.25 & $0.76-6.62$ & 0.14 \\
\hline Soft palate & 2 & 4 & 8.94 & $2.18-36.74$ & 0.002 \\
\hline Floor & 43 & 12 & 13.86 & $3.72-51.64$ & $<0.001$ \\
\hline Cheek & 15 & 5 & 9.31 & $2.77-31.33$ & 0.0003 \\
\hline \multicolumn{6}{|l|}{ p53 expression, \% } \\
\hline$\leq 50$ & 14 & 28 & $1.00^{\mathrm{a}}$ & & \\
\hline$>50$ & 82 & 26 & 5.59 & $3.23-9.67$ & $<0.001$ \\
\hline
\end{tabular}

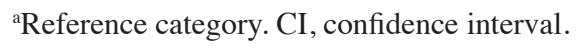



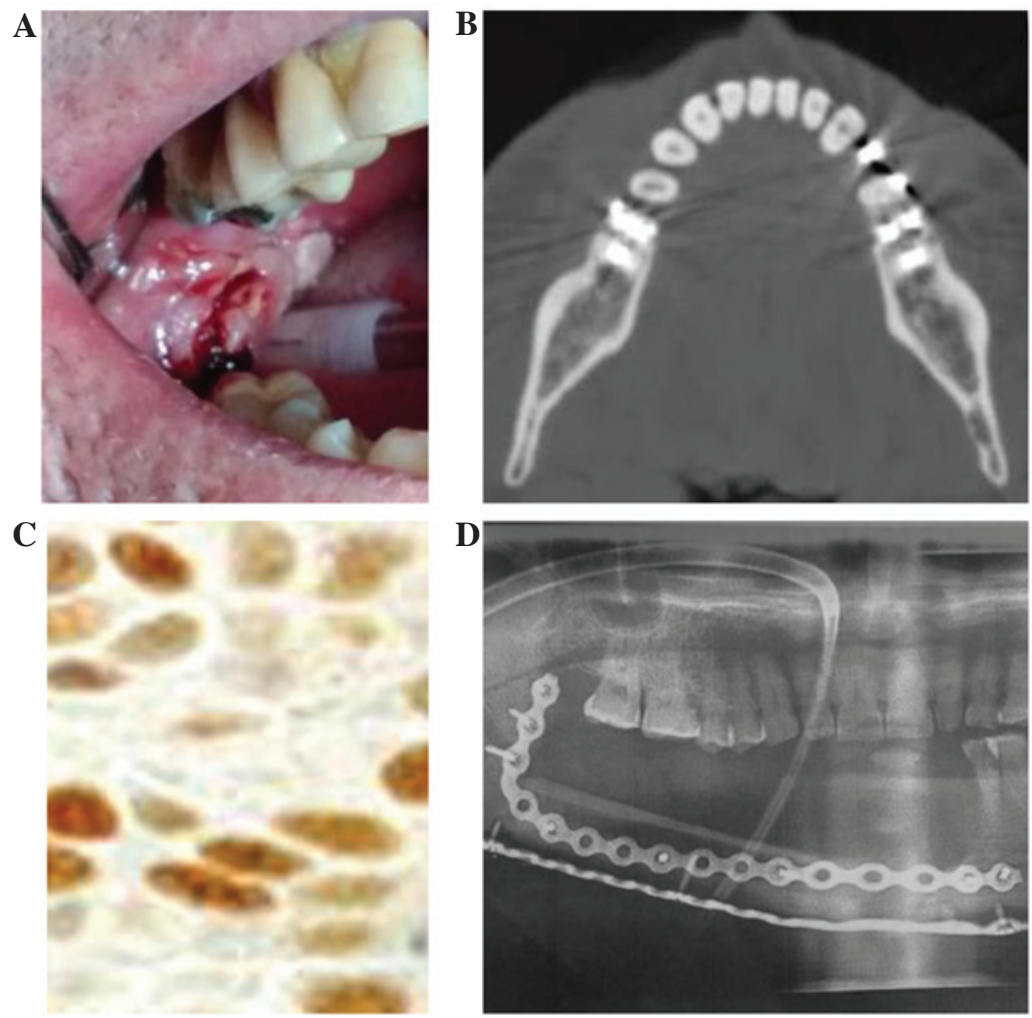

Figure 4. Stage I squamous cell carcinoma of the right retromolar trigone in a 59-year-old male. (A) Clinical aspect. (B) Contrast-enhanced computed tomography showing the absence of mandibular involvement. (C) p53 overexpression $>50 \%$ (streptavidin-biotin stain; original magnification, $\mathrm{x} 400$ ). (D) Follow-up after ablative surgery: Panoramic X-ray showing the mandibular reconstruction by revascularized free fibula flap.

15 males (64.5 \pm 5.6 years; range, $57-74$ years) and 12 females (69.2 \pm 3.9 years; range, 63-74 years); stage IVa, 42 males ( $66.9 \pm 5.3$ years; range, $55-75$ years), 16 females $(64.2 \pm 6.5$ years;

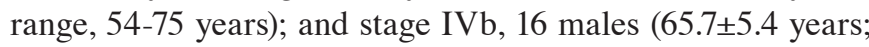
range, 57-74 years) and 1 female (69 years).

A significant association was found between the site of the tumor and p53 overexpression $(\mathrm{P}<0.0001)$. The distribution frequency of tumor site according to p53 overexpression was as follows: Tongue, $42.9 \%$; floor, $21.4 \%$; retromolar trigone, 11.9\%; attached gingiva, $9.5 \%$; and cheeks and soft palate, $7.1 \%$.

The cumulative survival rate of the entire group after 24 months of follow-up was $70.3 \%$ (standard error, 3.9). The results of the univariate analysis for the prognostic meaning of the main explanatory variables are shown in Table I. The log-rank test indicated that 3 prognostic factors were significantly correlated with prognosis. Stage I and stage II tumors showed a higher cumulative probability of 24 months of survival (97.9 and $96.3 \%$, respectively) compared with stage IVa and IVb (40.2 and $45.2 \%$, respectively) $(\mathrm{P}<0.0001)$. With regard to the site of tumor in the cohort examined, the cheek, the floor and the soft palate showed the worst prognosis when compared with tumors of the attached gingiva, tongue and retromolar trigone, with a cumulative probability of 24 months of survival at $22.2,25.9$ and $27.8 \%$, respectively $(\mathrm{P}<0.0001)$. Tumors with p53 overexpression $>50 \%$ showed a cumulative probability of a 24-month survival time of $47.4 \%$, while tumors with p53 expression $<50 \%$ showed a cumulative probability of $80.8 \%$ $(\mathrm{P}<0.0001)$ (Table I; Figs. 1-3). Table II shows the results of multivariate analysis, including the variables considered at the univariate analysis. Age ( $>65$ years), advanced tumor stage (stage IVa and IVb; RR=13.07 and 11.50, respectively), tumor location (soft palate, floor and cheek; RR=8.94, 13.86 and 9.31, respectively) and high p53 expression ( $>50 \%$; $\mathrm{RR}=5.59)$ were significantly associated with an increased risk of mortality.

A representative case of OSCC of the retromolar trigone is shown in Fig. 4.

\section{Discussion}

Knowledge of the oncogenetic pattern of a tumor can explain its natural history and behavior in single cases. Thus, a number of oncogenetic studies of oral cancer have been performed to identify prognostic and predictive markers (4-13).

The p53 tumor suppressor gene is correlated with oral tumor induction and progression, and its significant role as a prognostic marker was found in previous studies in advanced oral tumors (21).

The aim of the present study was to quantify the risk of mortality for all stages of OSCC. It is important to note that the cohort of patients considered was not consecutive due to the inclusion criteria used; thus, the distribution sites of the oral neoplastic lesions were different from those found in consecutive series.

Patients were selected on the basis of homogeneous G2 histopathological grading. This allowed more significance to be assigned to acquired data, as even more emphasis could be placed, in the single case, on the oncogenetic pattern and the specific biological features of neoplastic tissue, and the association with the risk of mortality. Three prognostic factors were found to be significantly associated with the prognosis. 
These results fulfill the aim of the present study. The study also shows that an age of $>65$ years is a variable that has an effect on survival, significantly increasing the risk of mortality compared with an age of $<65$ years. In addition, it is important to highlight the fact that patients with a floor tumor site exhibited a significantly higher risk of mortality than other sites.

Surgery is the main treatment for OSCC. Advanced oral tumors require wide resections and complex reconstruction using multimodal protocols $(25,26)$. Basic cancer research results are useful for maxillofacial surgeons and oncological teams in the management of the stage IV, but the possibility of having prognostic markers is perhaps even more important for the stages I and II.

Indeed the association found between p53 overexpression and the tumor site increases the indications for a wide resection associated with a prophylactic selective neck dissection in cases of T1-T2 N0 localized tumors of the tongue, the floor of the mouth, the retromolar trigone and the attached gingiva, but also in the cheek and soft palate, particularly when p53 overexpression results are $>50 \%$ (Fig. 4) (27). A previous study verified that $50 \%$ linked p53 antibody in histopathological specimens appears to be a significant cut-off value. Percentages $>50 \%$ of the expressed oncogene show a high probability of genetic mutation, which compromises the genic product and its related cellular function (21).

In the present study, survival analyses of the examined cases of OSCC show that four variables have an effect on survival, with a significantly increased risk of mortality: An age $>65$ years; an advanced stage, IVa and IVb; the site of the tumor; and p53 immunoexpression $>50 \%$.

These data indicated that, in oral cancer, every variable that was considered, such as tumor site, showed a worse prognosis, particularly when correlated with an altered p53 expression pattern. This can explain the natural history and behavior of the tumor, and the prognosis in single cases, while the classic clinical and radiological parameters, humoral markers and histopathological grading are not reflective.

The results of the present study allowed the quantification of the risk of mortality for OSSC with regard to the stage, the site and the p53 expression pattern of the tumor. The results also emphasized the importance of preliminary knowledge of the pattern of p53 as a prognostic marker of survival in order to obtain the best chance for a cure for these tumors in terms of the best surgical and therapeutic options.

\section{References}

1. Durmus K, Apuhan T and Ozer E: Transoral robotic surgery for retromolar trigone tumours. Acta Otorhinolaryngol Ital 33: 425-427, 2013

2. Freudlsperger C, Bodem JP, Engel E and Hoffmann J: Mandibular reconstruction with a prefabricated free vascularized fibula and implant-supported prosthesis based on fully three-dimensional virtual planning. J Craniofac Surg 25: 980-982, 2014.

3. Bànkfalvi A and Piffkò J: Prognostic and predictive factors in oral cancer: The role of the invasive tumor front. J Oral Pahol Med 29: 291-298, 2000.

4. Jan JC, Hsu WH, Liu SA, Wong YK, Poon CK, Jiang RS, Jan JS and Chen IF: Prognostic factors in patients with buccal squamous cell carcinoma: 10-year experience. J Oral Maxillofac Surg 69 396-404, 2011

5. Liao CT, Huang SF, Chen IH, Kang CJ, Lin CY,Fan KH, Wang HM, $\mathrm{Ng} \mathrm{SH}$, Hsueh C, Lee LY, et al: Outcome analysis of patients with pN2 oral cavity cancer. Ann Surg Oncol 17: 1118-1126, 2010.
6. Holmes JD, Martin RA and Gutta R: Characteristics of head and neck cancer patients referred to an oral and maxillofacial surgeon in the United States for management. J Oral Maxillofac Surg 68: 555-561, 2010.

7. Pérez-Sayáns M, Somoza-Martín JM, Barros-Angueira F, Reboiras-López MD, Gándara Rey JM and García-García A: Genetic and molecular alterations associated with oral squamous cell cancer (Review). Oncol Rep 22: 1277-1282, 2009.

8. Schwartz JL: Biomarkers and molecular epidemiology and chemoprevention of oral carcinogenesis. Crit Rev Oral Biol Med 11: 92-122, 2000

9. Shah NG, Trivedi TI, Tankshali RA, Goswami JA, Shah JS, Jetly DH, Kobawala TP, Patel KC, Shukla SN, Shah PM and Verma RJ: Molecular alterations in oral carcinogenesis: Significant risk predictors in malignant transformation and tumor progression. Int J Biol Markers 22: 132-143, 2007.

10. Shah NG, Trivedi TI, Tankshali RA, Goswami JV, Jetly DH, Shukla SN, Shah PM and Verma RJ: Prognostic significance of molecular markers in oral squamous cell carcinoma: A multivariate analysis. Head Neck 31: 1544-1556, 2009.

11. Shillitoe EJ, May M, Tale V, Lethanakul C, Enseley JF, Strausberg RL and Gutkind JS: Genome-wide analysis of oral cancer-early results from the cancer genome anaromy project. Oral Oncol 36: 8-16, 2000

12. Murugan AK, Munirajan AK and Tsuchida N: Ras oncogenes in oral cancer: The past 20 years. Oral Oncol 48: 383-392, 2012.

13. Saito T, Nakajima T and Mogi K: Immunohistochemical analysis of cell cycle-associated proteins p16, pRb, p53, p27 and Ki-67 in oral cancer and precancer with special reference to verrucous carcinoma. J Oral Pathol Med 28: 226-232, 1999.

14. Sidransky D, Boyle J and Koch W: Molecular screening. Prospects for a new approach. Arch Otolaryngol Head Neck Surg 119: $1187-1190,1993$

15. Boyle JO, Hakim J, Koch W, van der Riet P, Hruban RH, Roa RA, Correo R, Eby YJ, Ruppert JM and Sidransky D: The incidence of p53 mutations increases with progression of head and neck cancer. Cancer Res 53: 4477-4480, 1993.

16. Jones A: A general review of the $\mathrm{p} 53$ gene and oral squamous cell carcinoma. Ann R Australas Coll Dent Surg 14: 66-69, 1998.

17. Nylander K, Dabelsteen E and Hall PA: The p53 role molecule and its prognostic role in squamous cell carcimonas of the head and neck. J Oral Pathol Med 29: 413-425; 2000.

18. Tandon S, Tudur-Smith C, Riley RD, Boyd MT and Jones TM: A systematic review of p53 as a prognostic factor of survival in squamous cell carcinoma of the four main anatomical subsites of the head and neck. Cancer Epidemiol Biomarkers Prev 19: 574-587, 2010.

19. Cutilli T, Papola F and Corbacelli A: p53 overexpression and mutation, chemoresistance and patient survival in oral and maxillofacial squamous carcinoma. J Chemother 9: 123-124, 1997.

20. Cutilli T, Papola F, Di Emidio P and Corbacelli A: p53 tumor suppressor protein and H-RAS oncogene in maxillofacial tumors: Immunohistochemical and genetic investigaion, induction chemotherapy response and prognosis evaluation. J Chemother 10: 411-417, 1998.

21. Cutilli T, Leocata P, Dolo V and Altobelli E: Evaluation of p53 protein as a prognostic factor for oral cancer surgery. Br J Oral Maxillofac Surg 51: 922-927, 2013.

22. Green FL, Page DL, Fleming ID, Fritz AG, Balch CM, Haller DG and Morrow M (eds): AJCC cancer staging manual. 6th edition. Springer, New York, 2002.

23. World Health Organization. IARC monographs on the evaluation of carcinogenic risks to humans: Biological Agents. Volume 100B A review of human carcinogens. International Agency for Research on Cancer, Lyon, 2012.

24. Greene FL, Page DL, Fleming ID, Fritz AG, Balch CM, Haller DG and Morrow M (eds): AJCC Cancer Staging Manual. 6th edition, Springer-Verlag, New York, NY, 2002.

25. Specenier P and Vermorken JB: Advances in the systemic treatment of head and neck cancers. Curr Opin Oncol 22: 200-205, 2010.

26. Jenwitheesuk K, Surakunprapha P, Chowchuen B, Tangvoraphongchai V, Pesee M, Krusun S and Supaadirek C: Results of multidisciplinary therapy of squamous cell carcinoma of the buccal mucosa at Srinagarind Hospital, Thailand. J Med Assoc Thai 93: 1262-1267, 2010.

27. Hakeem AH, Pradhan SA, Tubachi J and Kannan R: Outcome of per oral wide excision of T1-2 N0 localized squamous cell cancer of the buccal mucosa-analysis of 156 cases. Laryngoscope 123: 177-180, 2013. 